\title{
Evaluation of microscopic methods in the diagnosis of idiopathic steatorrhoea
}

\author{
B. K. PATNAIK \\ From the Department of Pathology, Edinburgh University
}

SYNOPSIS Of 14 cases of clinically and biochemically confirmed idiopathic steatorrhoea, 11 showed mucosal abnormalities when biopsy specimens from the upper small intestine were examined under 0 the dissecting, the light, and the electron microscope. In the three remaining cases mucosal changes could be detected only under the electron microscope. The simple and inexpensive dissecting $N$ microscope can therefore be accepted as an efficient instrument for routine use in the diagnosis of 은 idiopathic steatorrhoea and for the screening of cases which might merit further examination under $\vec{C}$ the electron microscope. The light microscope allows the heights of the villi and the depth of the $\mathbb{D}_{D}^{\mathcal{D}}$ glandular layer to be measured and the limits of normality to be defined on a quantitative basis.

The electron microscope reveals abnormalities in the microvilli of mucosal epithelial cells. The $\frac{\mathbb{0}}{3}$ mildest changes consist of shortening and fusion of the microvilli and a lessened electron-density of $\stackrel{\mathbb{Q}}{-}$ the apical cytoplasm. Since these changes occur in mucosae which appear to be normal under the $\vec{\bullet}$ dissecting and the light microscope they are assumed to be related to the earlier stages of the disease $\stackrel{\circ}{v}$ and their significance is discussed in the light of this view.

Since the introduction of the peroral biopsy capsule (Crosby and Kugler, 1957) the morphological study of small intestinal mucosa has become a routine procedure in the investigation of idiopathic steatorrhoea. The mucosal abnormalities found have been studied under the dissecting, the light, and the electron microscope (Ashworth, Chears, Sanders, and Pearce, 1961; Padykula, Strauss, Ladman, and Gardner, 1961; Shearman, Girdwood, Williams, and Delamore, 1962; Shiner, Lacy, and Hudson, 1962; Rubin, Brandborg, Flick, MacDonald, Parkins, Parmentier, Phelps, Sribhibhadh, and Trier, 1962; Curran and Creamer, 1963), but the practical applications of this work to the diagnosis of the disease have yet to be assessed. Is the simple and inexpensive dissecting microscope adequate for routine use? Is light microscopy necessary? How often, if at all, must the costly and complicated electron microscope be used? The present work attempts to provide answers to such questions by comparing the results of all three methods of microscopy in a series of cases of idiopathic steatorrhoea already diagnosed on clinical and biochemical grounds.

\section{MATERIALS AND METHODS}

The specimens of upper small intestinal mucosa which Received for publication 29 March 1967. were examined came from two groups of patients: the controls, 17 patients without intestinal disease, and the $\frac{\circ}{\square}$ disease group, 63 patients, with steatorrhoea alone, or $\varrho$ steatorrhoea and megaloblastic anaemia, admitted to the $\overrightarrow{\vec{\sigma}}$ Royal Infirmary, Edinburgh between 1959 and 1964. (The 3 clinical and biochemical findings are given in a detailed account of this group by Girdwood, Williams, McManus, Dellipiani, Delamore, and Kershaw, 1966.) All specimens were examined under the light and the dissecting micro- $\frac{?}{0}$ scope; six from the control group and 14 from the disease 0 group were also examined under the electron microscope.

In 28 of the diseased group peroral biopsy capsule $?$ specimens were obtained from the upper part of the $\frac{0}{3}$ jejunum, localization of the capsule being controlled 0 fluoroscopically. In the remaining $\mathbf{3 5}$ of the disease group paraffin blocks of previous biopsy specimens were avail- $D$ able both routinely fixed and specially prepared for elec- 을. tron microscopy. Sections from these were examined $N$ under the light and electron microscope respectively while $\sigma$ for dissecting microscopic examination the tissues were $N$ cut out of the blocks, cleared in xylol, passed through $\mathrm{N}$ descending grades of alcohol into $10 \%$ alcohol, and $\underset{\sigma}{\sigma}$ examined.

\section{RESULTS}

DISSECTING MICROSCOPE CHANGES In the controls, the upper jejunal mucosa showed a pattern of 'finger' and 'leaf' villi in various combinations.

In the disease group, the least affected mucosae showed replacement of villi by 'ridges' and 'con- $\frac{0}{\sigma}$ 
volutions'. Others showed a mosaic pattern of domelike protuberances replacing the villi. The most severely affected mucosae were featureless and flat.

LIGHT MICROSCOPIC CHANGES In the controls, tall finger-like villi predominated in the mucosa (Fig. 1).

In the disease group, the milder abnormalities ranged from partially fused villi to short, broad, clubshaped villi, both being associated with increased round cell infiltration of the stroma and a slight increase in mitotic activity in the covering epithelium. The grosser changes involved progressive shortening and broadening of the villi until they ultimately became mere undulations of the mucosal surface. At the same time chronic inflammatory cells infiltrated among the surface epithelial cells and plasma cells became conspicuous in the stroma. Striking changes also occurred in the epithelial cells of the basal part of the mucosa. The crypts of Lieberkühn became dilated, elongated and tortuous while the basal glands assumed a racemose form with two or three glands entering each crypt (Fig. 2). The mitotic activity of the mucosal epithelium was notably increased.

Micrometric measurements of the height of the villi and the depth of the glandular layer were used to give quantitative expression to the abnormalities noted above. In the normal jejunal mucosa, as judged by the measurements in the control group, villi varied from $350 \mu$ to $550 \mu$ in height (Fig. 3) and the glandular layer was never more than $200 \mu$ in depth.

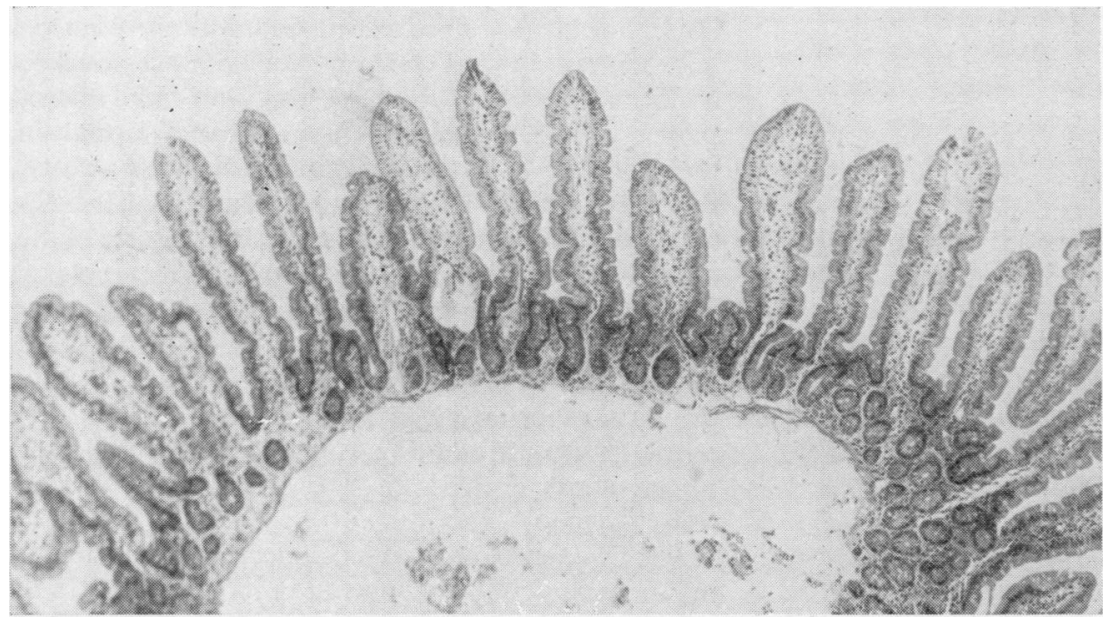

FIG. 1. Normal jejunal mucosa. (H.E. $\times$ 40.)

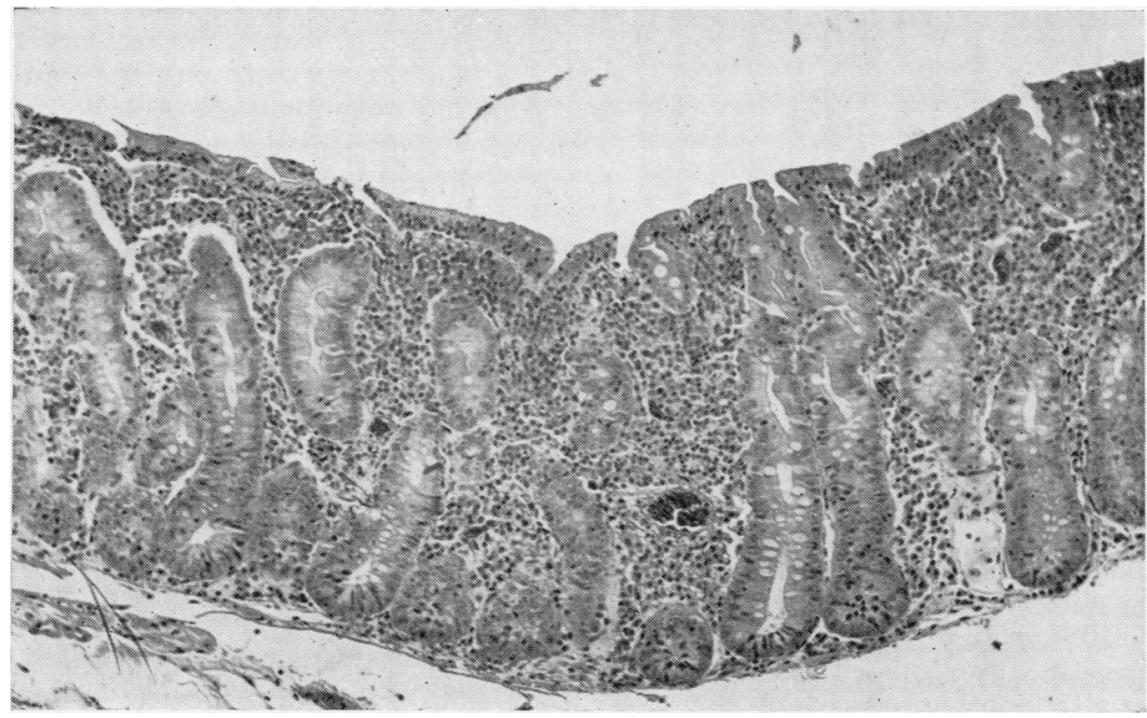

FIG. 2. 'Flat' jejunal mucosa in idiopathic steatorrhoea. Absence of villi, hypertrophy of basal glands, cellular infiltration. Two glands are seen entering $a$ crypt of Lieberkühn at the arrow point. (H.E. $\times$ 80.) 


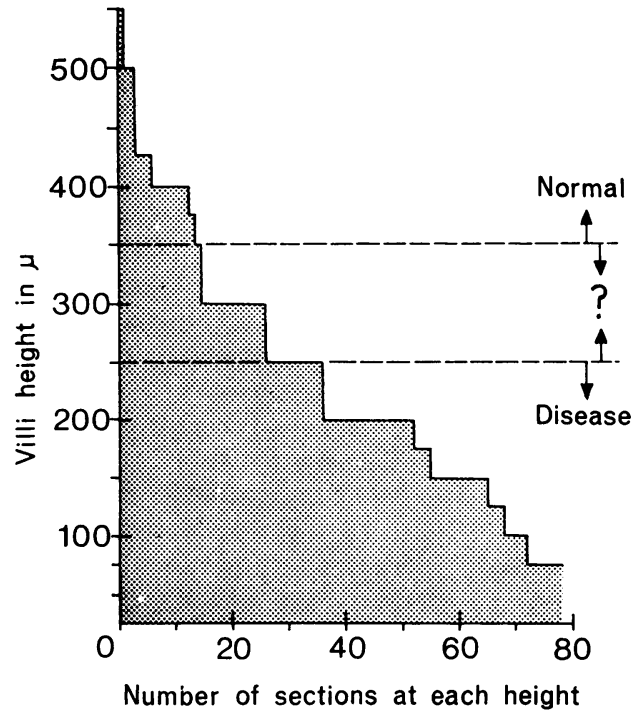

FIG. 3. Height of villi used as a screening test. In the zone 250-350 $\mu$ the distinction between normal and abnormal can only be made by the use of the electron microscope.

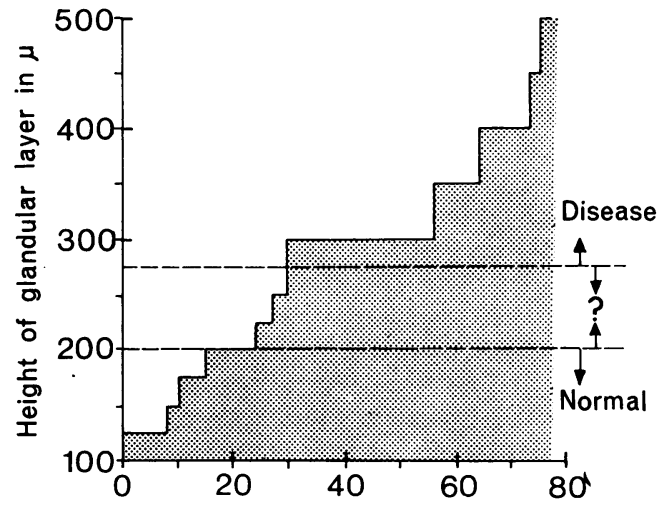

Number of sections at each height

FIG. 4. Height of glandular layer as screening test. Electron microscopy reveals abnormalities in the intermediate zone 200-275 $\mu$ between normal and abnormal.

In patients with idiopathic steatorrhoea the height of the jejunal villi lay in the range $75 \mu$ to $250 \mu$ and the depth of the glandular layer was never less than $275 \mu$ (Fig. 4). In specimens where the measurements of villous height and glandular depth either separately or together fell in the range between normal and abnormal, that is $250 \mu$ to $350 \mu$ for the villous height and $200 \mu$ to $275 \mu$ for the glandular depth, electron microscopy revealed certain abnormal features which are considered later. Thus these measurement䲩 provide a screening device for the selection of specimens meriting examination under electron micro $\frac{5}{5}$ scope.

ELECTRON MICROSCOPE CHANGES The study of the्ष ultrastructure of intestinal mucosa was limited to the upper third of the villus.

Control group Under the electron microscope the mucosal surface of the villous epithelial cells was seerw to be covered by finger-like processes (microvilli) fion $0.85 \mu$ to $1.20 \mu$ long arranged in a pattern of regula hexagons. The cytoplasm in the cores of the microvillip was continuous with agranular cytoplasm of the apical part of the cell.

Disease group Of 14 specimens from patients witto idiopathic steatorrhoea examined under the electron microscope, 11 had already shown well markeds abnormalities under the dissecting and light microe scope, while the remaining three appeared normal. In the group of 11 patients the microvilli were scantyo short, irregular in shape, and were distributed uneven= ly instead of in regular hexagons on the surface of theo cells. The mitochondria of the supranuclear cytoplasm was swollen and rounded, the outer and innec limiting membranes tended to be fused together, and the internal structure was completely disorganized the matrix appearing in places to encroach on the cristae (Fig. 5). In addition, round or oval cytoplasmi bodies were noticed in the supranuclear region (Fig. 6).

The three specimens which appeared normal under the dissecting and the light microscope showed welf marked changes under the electron microscope. The microvilli were somewhat shorter than normal (lese than $0.6 \mu$ in height) and in cross section exhibited cuboidal instead of a hexagonal pattern. The cyto plasm was slightly less electron-dense, probably aio effect of oedema in the apical part of the cell. In someె places the microvilli had become partially or com? pletely fused together (Fig. 7). In these fused micro $>$ villi the plasma membrane at the site of contact has become dissolved so as to allow continuity between the cores of the microvilli. The site of fusion was very variable, affecting the whole length of some villi, the middle third of others, and in others again the greater part of the length leaving only the tips freeg The contents of the fused microvilli were often less electron-dense than normal (Patnaik, 1966).

Since one of the cases showing fusion of microvilf had rheumatoid arthritis mucosal specimens fromo four other patients with rheumatoid arthritis were examined, but since none of them showed this features the possibility of its being due to rheumatoid arthritis may be excluded. It may be noted that two of the 


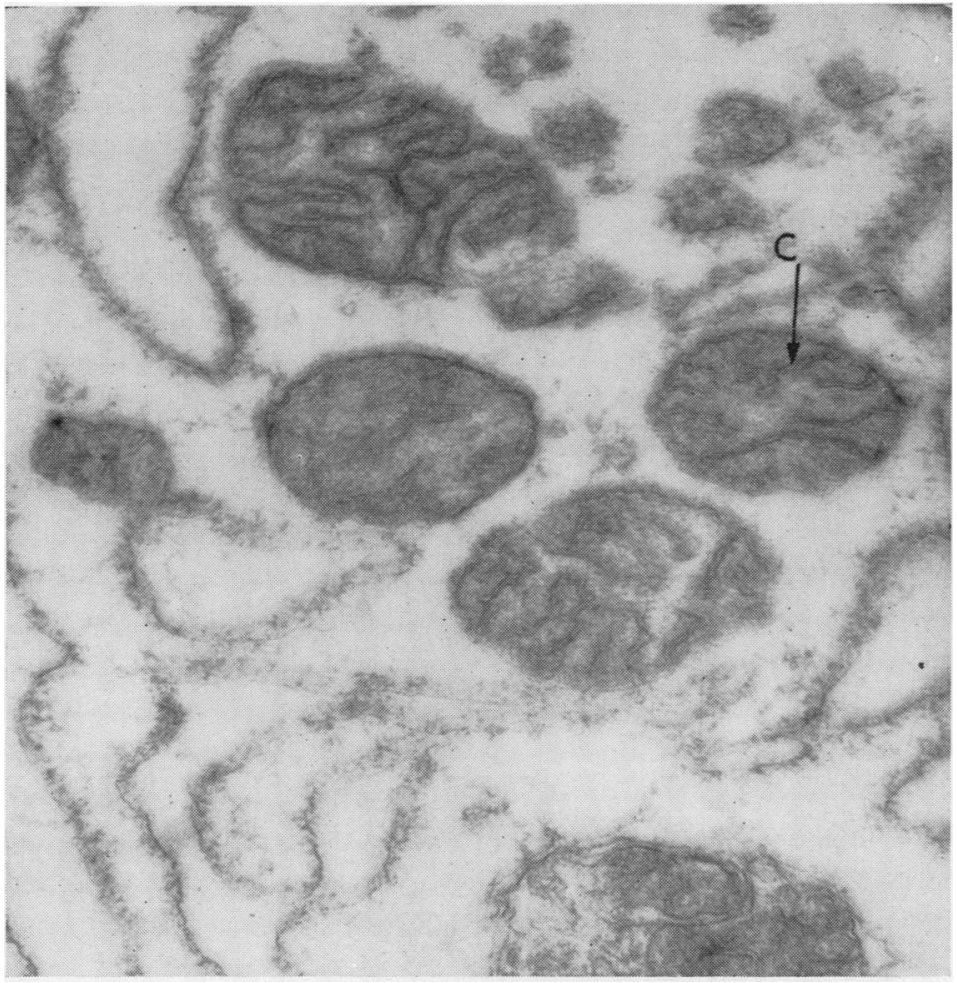

FIG. 5. Electron micrograph of jejunal mucosal cell from a case of idiopathic steatorrhoea. The swollen mitochondrial matrix encroaches on the cristae $(C)$ of the mitochondria. $(\times 60,000)$.

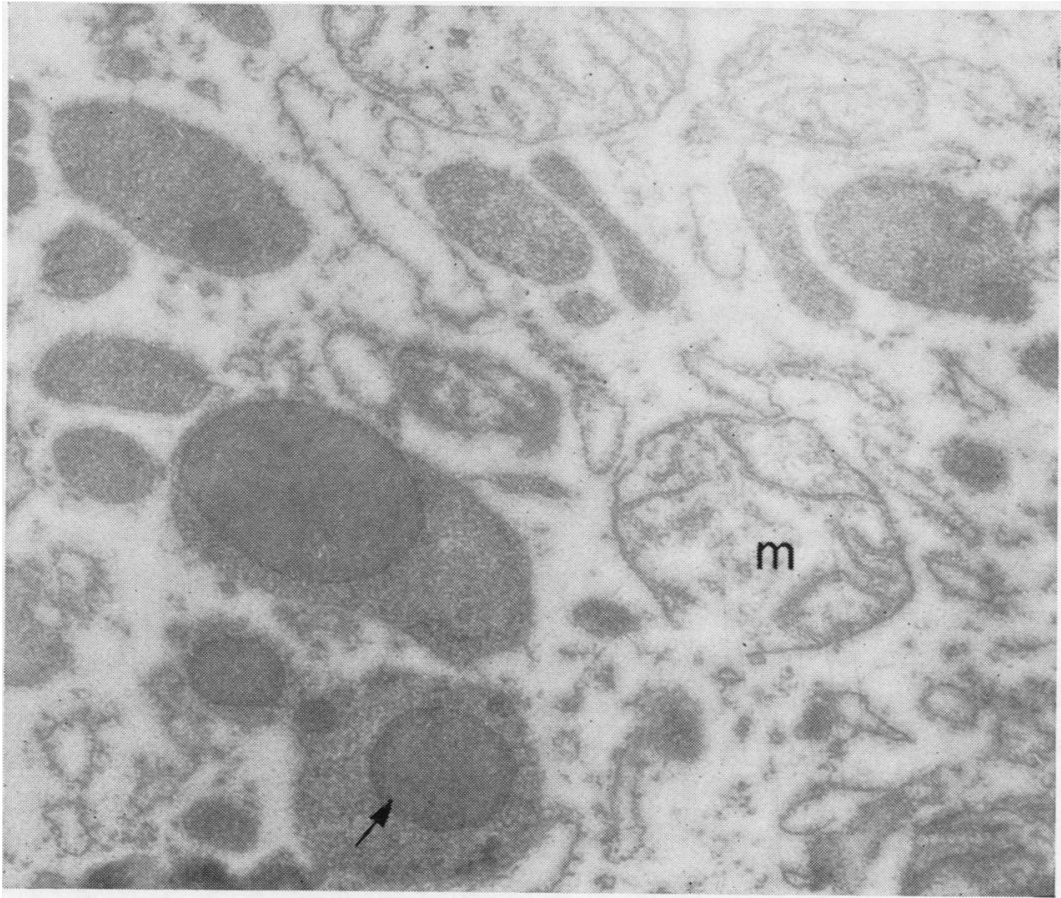

FIG. 6. Electron micrograph of jejunal mucosal cell from a case of idiopathic steatorrhoea. The pointer indicates osmiophilic granule in the cytoplasm the mitrochondria $(m)$ are swollen. $(\times 56,000$. 


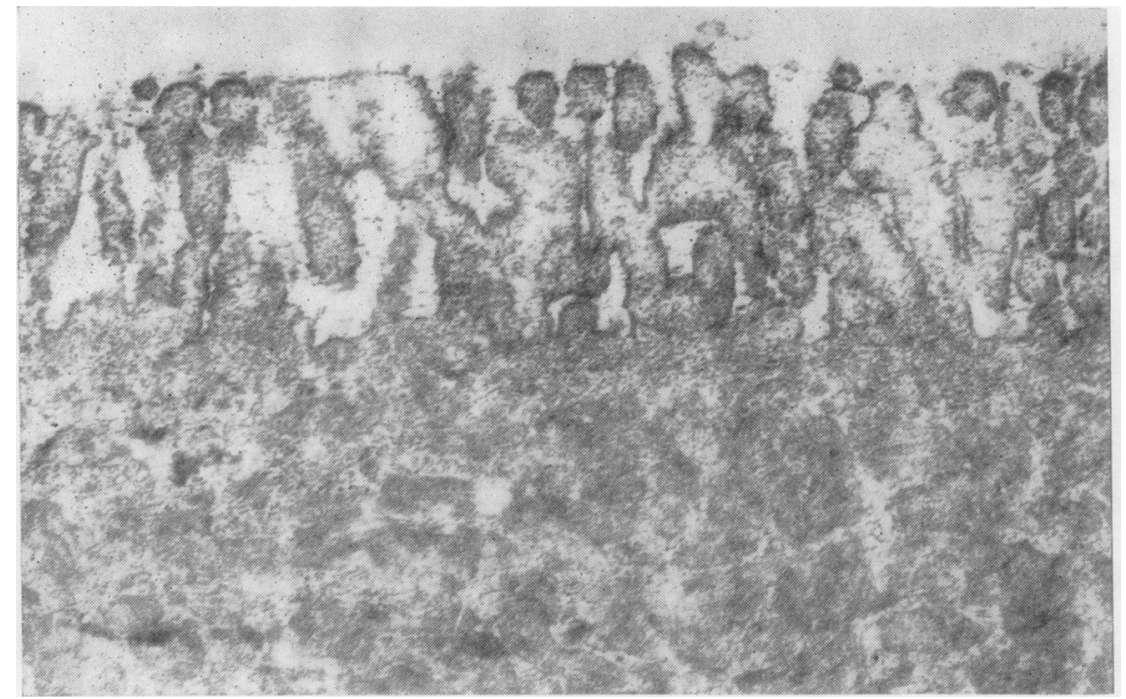

FIG. 7a. Electron micrograph showing fusion of microvilli $(\times 28,000)$, less severe than in Figure $7 \mathrm{~b}$.

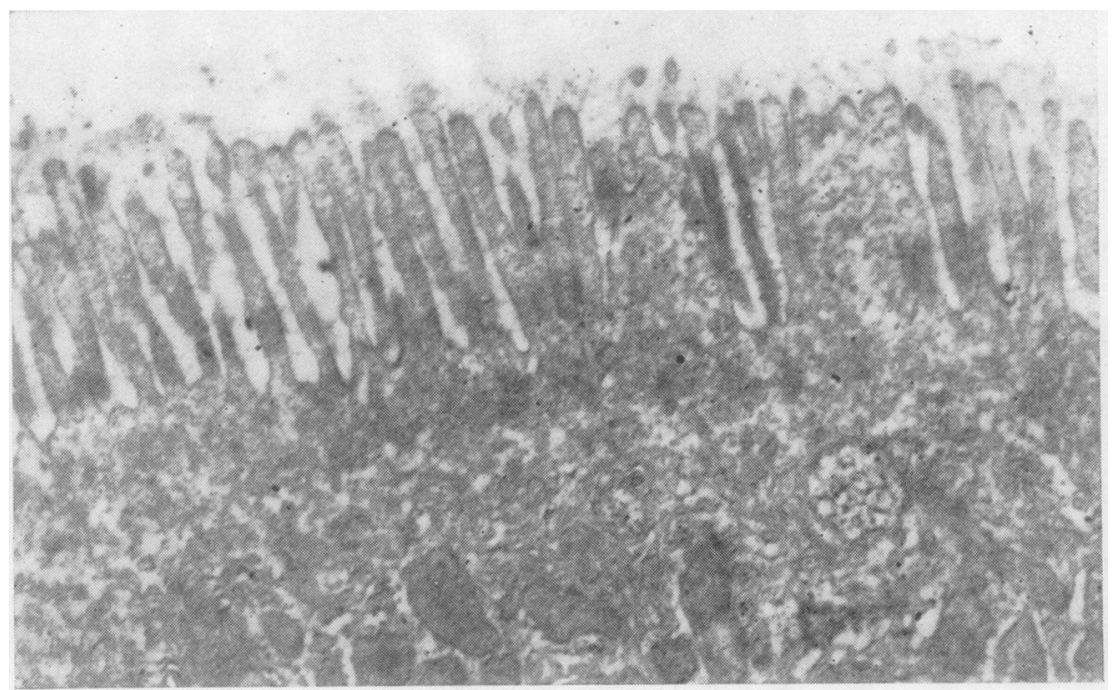

FIG. 7b. Electron micrograph showing fusion of microvilli $(\times 30,000)$.

specimens from the larger group of 11 patients also showed some degree of fusion of microvilli.

\section{DISCUSSION}

The results of the study show that in $95 \%$ of a series of cases of idiopathic steatorrhoea in which the diagnosis had already been confirmed clinically and biochemically, mucosal abnormalities were visible under the dissecting, the light, and the electron microscope (Fig. 8). The dissecting microscope showed advantages over the light microscope in enabling a larger area of mucosa to be surveyed, the mosaic distribution of mucosal changes to be apprec- iated, and different type of abnormality to beo distinguished clearly one from another. Under the light microscope 'finger', 'leaf', and 'ridge' formson may easily be confused if the section under examin- $N$ ation is small and obliquely cut. This defect of lighto microscopy is slightly offset by the single small advantage which it offers, namely, the possibility of measuring the height of the villi and the depth of the glandular layer. These measurements were found too furnish a slightly more sensitive indication of abnormality than could be gained by the mucosal appearance.

The comparison therefore suggests that in the great majority of cases of idiopathic steatorrhoea the 


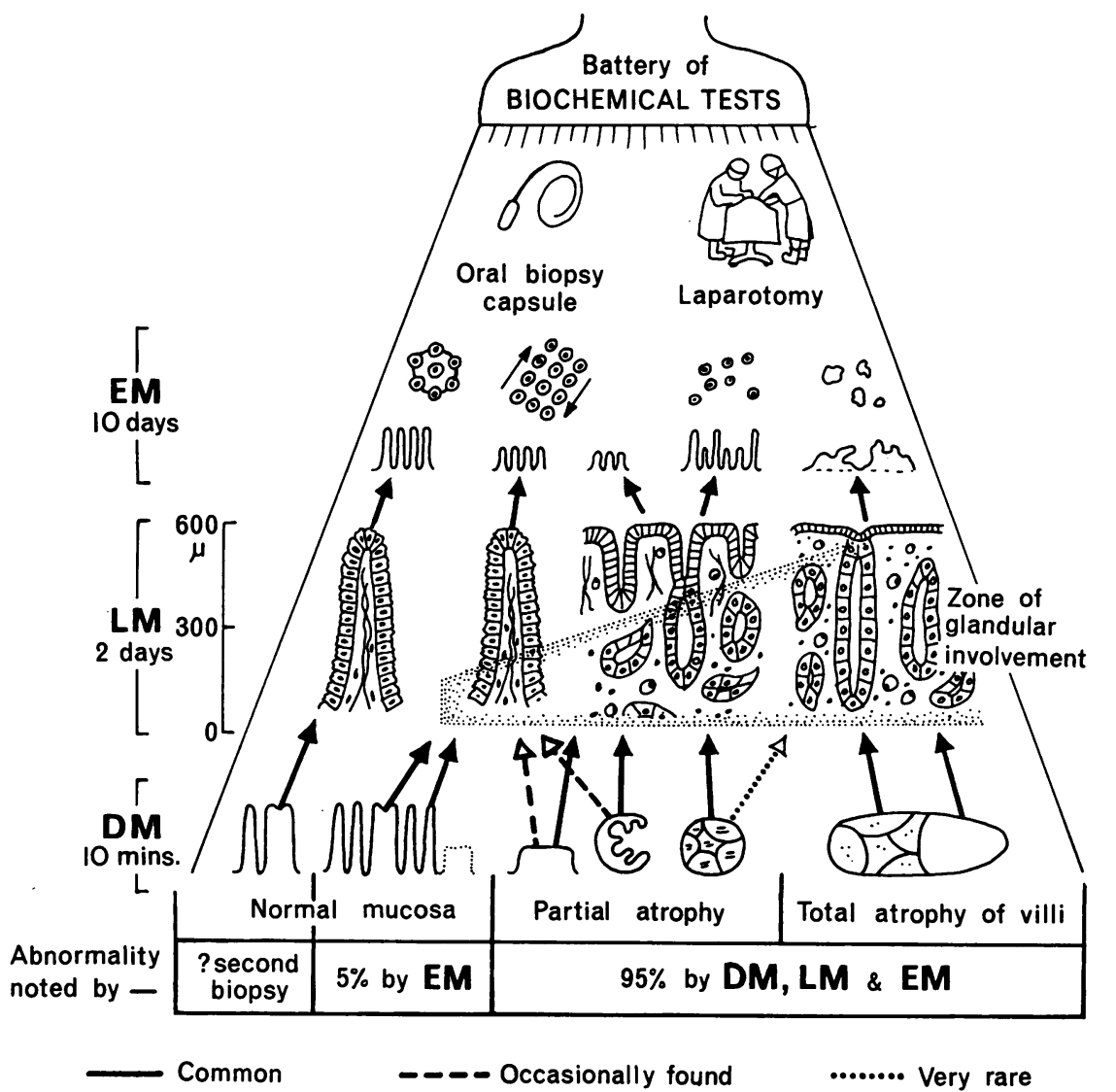

FIG. 8. Diagrammatic representation and comparison of methods of investigation in idiopathic steatorrhoea. $E M=$ electron microscope; $D M=$ dissecting microscope, LM = light microscope.

simple and inexpensive dissecting microscope can be thoroughly recommended as an efficient aid to diagnosis. It is probably slightly superior to the light microscope for this purpose.

It would appear also that the electron microscope has only a small part to play in the routine investigation of idiopathic steatorrhoea. In the present series electron microscopy consistently showed abnormaliities of fine structure in the mucosal epithelial cells of cases in the disease group but since $95 \%$ of these were already abnormal under the dissecting microscope the necessity for electron microscopy seems to be limited to the remaining $5 \%$ which escape detection on screening by the dissecting microscope. Even in this small field the usefulness of electron microscopy is minimized by the fact that the cases concerned had already been diagnosed on clinical and biochemical grounds.

The changes in the microvilli revealed by the elec- tron microscope in the present series may throw some light on the pathogenesis of the disease. In the cases where the mucosa was normal under the dissecting and the light microscopes, electron microscopy showed that the microvilli were unusually small, were to some extent fused together, and showed a less electron-dense cytoplasmic core, a change which was also observed in the agranular cytoplasm below the attachment of the microvilli in these specimens. As fusion of the microvilli was found only in five cases, three of which were otherwise morphologically normal, it is assumed to be a feature of a very early stage of idiopathic steatorrhoea and to precede the shortening, irregularity in shape, and unequal distribution of microvilli seen in the other cases. It seems possible that fusion of the microvilli might be observed in cases where the disease is still in a subclinical state. It may perhaps be suggested furthermore that fusion, by reducing the flexibility of the 


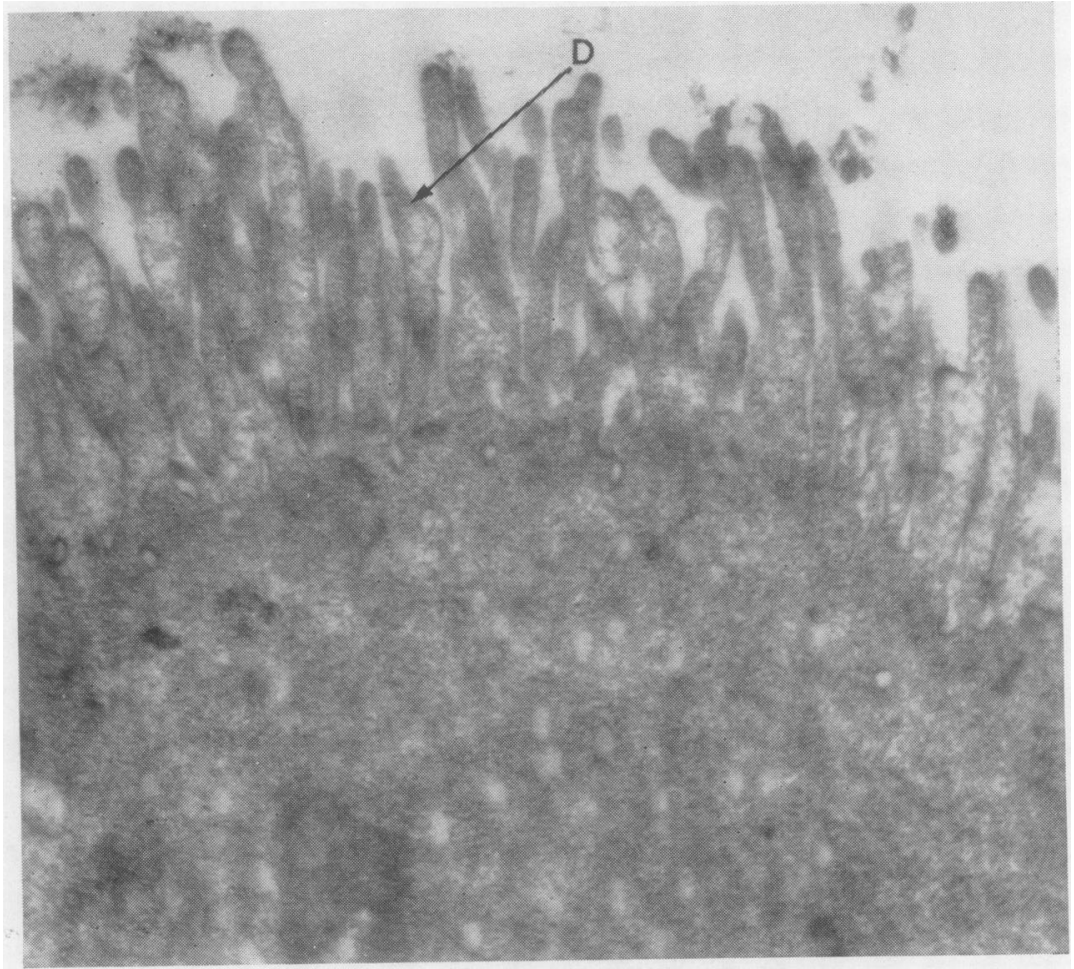

FIG. 9. Electron micrograph to illustrate artefacts produced by delayed fixation of jejunal mucosa. Fusiform dilatation $(D)$ of upper part of microvilli. $(\times 40,000)$.

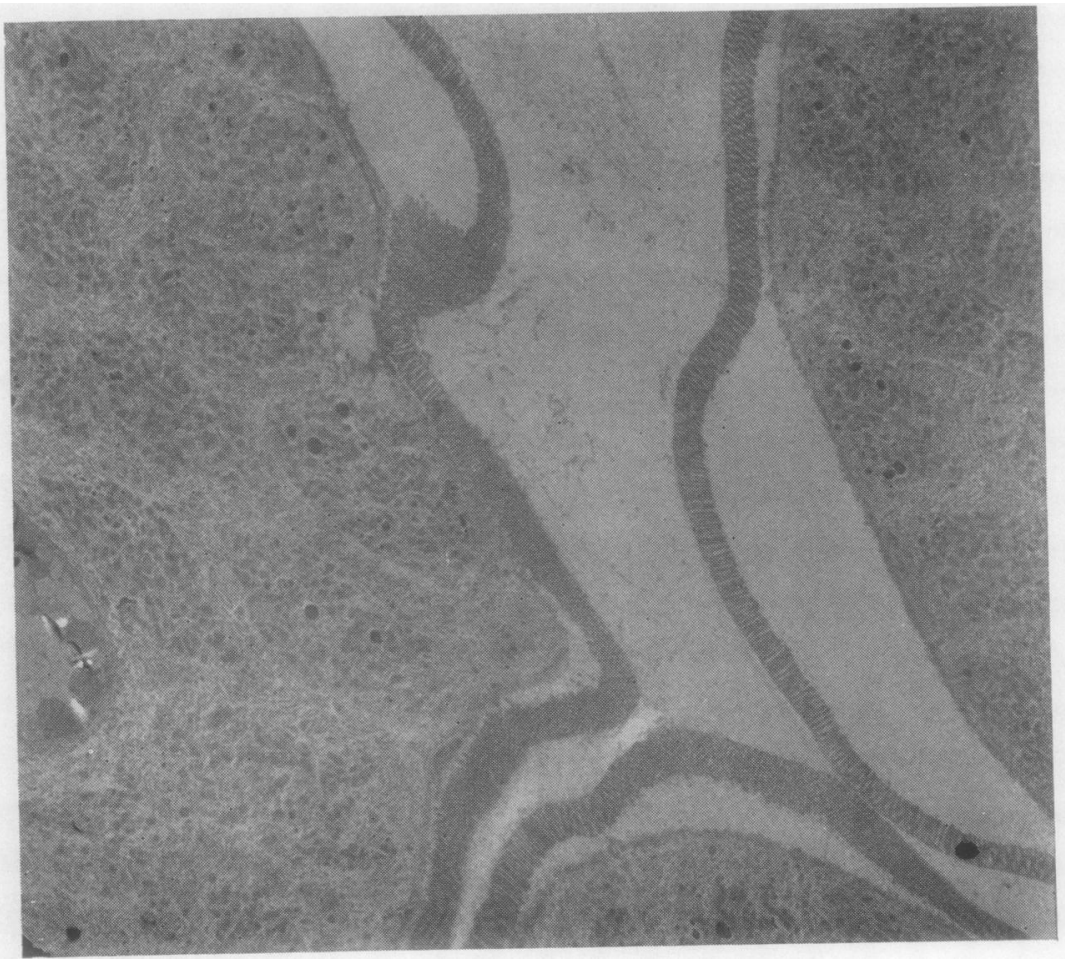

FIG. 10. Electron micrograph showing artefacts produced by inadequate dehydration of specimens of jejunal mucosa. The layer of microvilli has become detached from the surface of the villus. $(\times 1,950)$. 
microvilli, predisposes to their traumatization by the passage of intestinal contents. The fused microvilli being less able to yield to the pressures applied to them could become distorted in shape or even torn from the cell surface. Such could be the explanation of the bizarrely shaped microvilli and their loss seen in the advanced cases of idiopathic steatorrhoea in this series. The gross changes in the microvilli in cases of the established disease are in fact presumed to be the end result of the process of fusion, which is the first abnormality in the disease and one that can only be detected by the electron microscope.

It might be objected that the changes in the microvilli could be due to autolysis from delayed fixation. This would be unlikely since precautions were taken to minimize the time lapse between obtaining the biopsy and putting it into the fixative. Moreover, delay in fixation gives rise not to fusion of microvilli but to fusiform dilatation of the upper third of the villi (Fig. 9), and to well-recognized changes in cytoplasm, mitochondria, and nucleus. None of these changes were present in the material examined.

Cutting artefacts and changes due to improper dehydration can also be excluded since both of these cause separation of the entire mass of the microvilli from the apical part of the cell (Fig. 10) and this was not observed.
I am grateful to Professor G. L. Montgomery for his encouragement and indebted to Dr. J. Murray Drennan for helpful criticism and guidance in writing this paper. I wish also to thank Professor R. H. Girdwood for allowing me to obtain material from his patients for study. The work was carried out during the tenure of a research fellowship in pathology from the University of Edinburgh.

\section{REFERENCES}

Ashworth, C. T., Chears, W. C., Jr., Sanders, E., and Pearce, M. B. (1961). Arch. Path., 71, 13.

Crosby, W. H., and Kugler, H. W. (1957). Amer. J. dig. Dis., 2, 236.

Curran, R. C., and Creamer, B. (1963). J. Path. Bact., 86, 1.

Girdwood, R. H., Williams, A. W., McManus, J. P. A., Dellipiani, A. W., Delamore, I. W., and Kershaw, P. W. (1966). Scot. med. J., 11, 343.

Padykula, H. A., Strauss, E. W., Ladman, A. J. and Gardner, F. H. (1961). Gastroenterology, 40, 735.

Patnaik, B. K. (1967). In Proc. 3rd Wld. Congr. Gastroent., Tokyo. In the press.

Rubin, C. E., Brandborg, L. L., Flick, A. L., MacDonald, W. C., Parkins, R. A., Parmentier, C. M., Phelps, P., Sribhibhadh, S. I., and Trier, J. S. (1962). In Intestinal Biopsy (Ciba Foundation Study Group, no. 14), edited by G. E. W. Wolstenholme and M. P. Cameron, p. 67. Churchill, London.

Shearman, D. J. C., Girdwood, R. H., Williams, A. W., and Delamore, I. W. (1962). Gut, 3, 16.

Shiner, M., Lacy, D., and Hudson, R. H. (1962). In Intestinal Biopsy (Ciba Foundation Study Group, no. 14), edited by G. E. W. Wolstenholme and M. P. Cameron, p. 24. Churchill, London. 